\section{Ethephon-mediated Changes in Gas Exchange of Tomato Plants}

\author{
Jan-W. Briedé, James T. Fisher, and Daniel J. Manuchia ${ }^{2}$ \\ Department of Agronomy and Horticulture, Box 3Q, New Mexico State \\ University, Las Cruces, NM 88003
}

Additional index words. photosynthesis, stomatal conductance, ethylene, Lycopersicon esculentum

Abstract. The gas exchange of tomato (Lycopersicon esculentum Mill cv. Spring Giant VF) plants exposed to an ethephon root drench of $5 \mu \mathrm{l} \cdot \mathrm{liter}^{-1}$ or $50 \mu \mathrm{l} \cdot \mathrm{liter}^{-1}$ was examined for 9 days. Photosynthesis showed a biphasic response to ethephon, wherein elevations of $13.2 \%$ and $16.7 \%$ were observed over control plants for two of the measurement days for the 50 and $5 \mu \mathrm{l}$ ethephon/liter concentrations, respectively. Stomatal conductance showed a large increase at $50 \mu \mathrm{l}$ ethephon/liter on day 2 , while $5 \mu \mathrm{l} \cdot \mathrm{liter}^{-1}$ did not show this difference. A biphasic response of photosynthesis may explain some of the intraspecific variation found in the literature describing ethylene-induced gasexchange alterations.

The literature reports neutral or adverse effects on growth and gas exchange of plants treated with ethylene. These effects include leaf epinasty, changes in carbon allocation, growth inhibition, aerenchyma development, chlorophyll destruction, flower inhibition, and flower-sex modification (Bradford, 1983; Tang and Kozlowski, 1984; Taylor and Gunderson, 1986, 1988; Woodrow et al., 1988). Most of these reports are based on short-term $(<48 \mathrm{~h})$ ethylene exposure. In a recent trial, we observed that long-term exposure to ethephon, an ethylene-releasing agent, enhanced foliar gas exchange of Pinus eldarica (Medin.) seedlings, but there were few short-term effects even at relatively high ethephon levels (Manuchia and Briedé, 1989). Long-term exposure to ethephon applied as a root drench at concentrations of 1000 $\mu \mathrm{l} \cdot$ liter $^{-1}$ increased stomatal conductance, transpiration rates, and, occasionally, photosynthesis throughout the 14-day observation period. Similarly, ethylene-induced enhancement of stomatal aperture was found in Vicia faba L. (Levitt et al., 1987) and Olea europaea L. (Vitagliano, 1975). Levitt

Received for publication 28 Jan. 1991. Accepted for publication 15 Aug. 1991. New Mexico State Univ. Agricultural Experiment Station Journal Article no. 1520. The cost of publishing this paper was defrayed in part by the payment of page charges. Under postal regulations, this paper therefore must be hereby marked advertisement solely to indicate this fact.

${ }^{\prime}$ To whom reprint requests may be addressed. Current address: Pittsburg \& Midway Coal Mining Co. (a Chevron Co.), P.O. Box 335, Gallup, NM 87305.

${ }^{2}$ Current address: Plant Propagation Technologies, P.O. Box 4292 UPB, Las Cruces, NM 88003. et al. (1987) observed ethylene-induced stomatal opening, which they concluded was similar to that seen after pathogen infection in $V$. faba. These findings implicate ethylene as a stress-mitigating hormone. In a subsequent study, Vitagliano and Hoad (1978) found that the ethylene-mediated increase in stomatal aperture with $O$. europaea was not observed consistently. Stomatal aperture in these experiments on $V$. faba and $O$. europaea were based solely on microscopic measurements and no gas-exchange measurements were taken.

There are few data available on the effects of long-term ethylene exposure on plants (Manuchia, 1990; Manuchia and Briedé, 1989; Woodrow et al., 1988). Based on our research with $P$. eldarica, which showed an increased stomata1 conductance and transpiration when plants were subjected to ethylene for longer than $48 \mathrm{~h}$, we hypothesized that gas-exchange response of plants exposed to ethylene for more than 2 days is species- and ethylene-concentration-dependent. Here our objective was to determine whether the gas-exchange response in tomato plants exposed to ethylene was similar to the responses in P. eldarica. Research with tomato using $300 \mathrm{mg}$ ethephon/liter applied as a foliar spray (Woodrow et al., 1988) or $4 \mu \mathrm{l}$ ethylene gas/liter (Bradford, 1983) revealed no short-term effect on stomatal conductance of tomato, while short-term exposure to 60 to 70 gaseous ethylene/liter was implicated in stomatal closure of tomato leaves (Madhavan et al., 1983). Preliminary work with tomato indicated the need to adjust the ethylene concentration to levels below 7.5 $\mu l \cdot$ liter $^{-1}$ to obtain responses similar to those seen in $P$. eldarica. Therefore, in the present study, we exposed tomato plants to 5 or 50 $\mu \mathrm{l} \cdot$ liter $^{-1}$ for 9 days.

Eighteen 'Spring Giant VF' tomato plants were grown from transplants in 2.8-liter containers in a greenhouse. The growing medium was a 2 peatmoss : 1 vermiculite mix $(\mathrm{v} / \mathrm{v})$. Ethephon treatments began when plants were $\approx 30 \mathrm{~cm}$ tall. Day temperatures in the greenhouse did not exceed 30C, whereas nights were maintained above 20C. Maximum photosynthetic photon flux (PPF) in the greenhouse was $1200 \mu \mathrm{mol} \cdot \mathrm{m}^{-2} \cdot \mathrm{s}^{-1}$ at solar noon. The plant material was divided into three treatments of six plants each. Treatments included a control (water only) and ethephon at 5 or $50 \mu \mathrm{l} \cdot$ liter $^{-1}$ prepared in deionized water and applied daily as a root drench. Plants were watered daily until the solution drained freely from the bottom of the pots. Ethylene gas released from the treatment solutions was analyzed using a Hewlett Packard 5840 gas chromatograph (Hewlett Packard, Palo Alto, Calif.) equipped with a flame ionization detector and an activated alumina column, operated at 100C. Gas samples $(5 \mathrm{ml})$ were drawn from the top $5 \mathrm{~cm}$ with a hypodermic syringe of the ethephon-soaked growing medium. Ethylene release was monitored for $24 \mathrm{~h}$. This duration was considered sufficient because in the greenhouse, the solution was re-applied to the containers every $24 \mathrm{~h}$, thus leaching the medium and replacing most of the air in the medium. Soil air samples indicated that ethylene release (2-24 h) did not exceed 23 $\mu \mathrm{l} \cdot$ liter $^{-1}$ air during this period (Table 1).

Gas exchange measurements were con-

Table 1. Ethylene release from ethephon. Ethephon was applied to the growing medium as a root drench.

\begin{tabular}{|c|c|c|c|}
\hline \multirow{3}{*}{$\begin{array}{l}\text { Time after } \\
\text { exposure } \\
\text { (h) }\end{array}$} & \multicolumn{3}{|c|}{ Ethephon concn $\left(\mu l \cdot\right.$ liter $\left.^{-1}\right)$} \\
\hline & 0 & 5 & 50 \\
\hline & \multicolumn{3}{|c|}{ Ethylene release $\left(\mu \mathrm{l} \cdot \mathrm{liter}^{-1}\right)^{2}$} \\
\hline 2 & $1.5 \pm 0.2$ & $3.7 \pm 1.2$ & $23.0 \pm 6.2$ \\
\hline 4 & $0.5 \pm 0.2$ & $3.9 \pm 1.9$ & $15.1 \pm 4.7$ \\
\hline 24 & $0.4 \pm 0.1$ & $1.4 \pm 1.0$ & $6.2 \pm 3.1$ \\
\hline
\end{tabular}

${ }^{2}$ Values are the mean of three determinations, \pm SE.

Table 2. Analysis of variance for polynomial concentration trends for ethephon applied at 5 or $50 \mu \mathrm{l} \cdot \mathrm{liter}^{-1}$ to tomato plants.

\begin{tabular}{llcccc}
\hline \hline Day & $\begin{array}{l}\text { Source of } \\
\text { variation }\end{array}$ & df & MS & F & $P$ value \\
\hline 2 & Ps $\times$ Concn (L) & 1 & 8.35 & 4.43 & 0.062 \\
2 & Ps $\times$ Concn (Q) & 1 & 6.46 & 3.43 & 0.094 \\
2 & Cm $\times$ Concn (L) & 1 & 0.177 & 4.32 & 0.065 \\
3 & Cm $\times$ Concn (L) & 1 & 0.245 & 5.94 & 0.035 \\
\hline
\end{tabular}

${ }^{2} \mathrm{Ps}=$ photosynthesis; $\mathrm{Cm}=$ stomatal conductance; $\mathrm{L}=$ linear; $\mathrm{Q}=$ quadratic. 

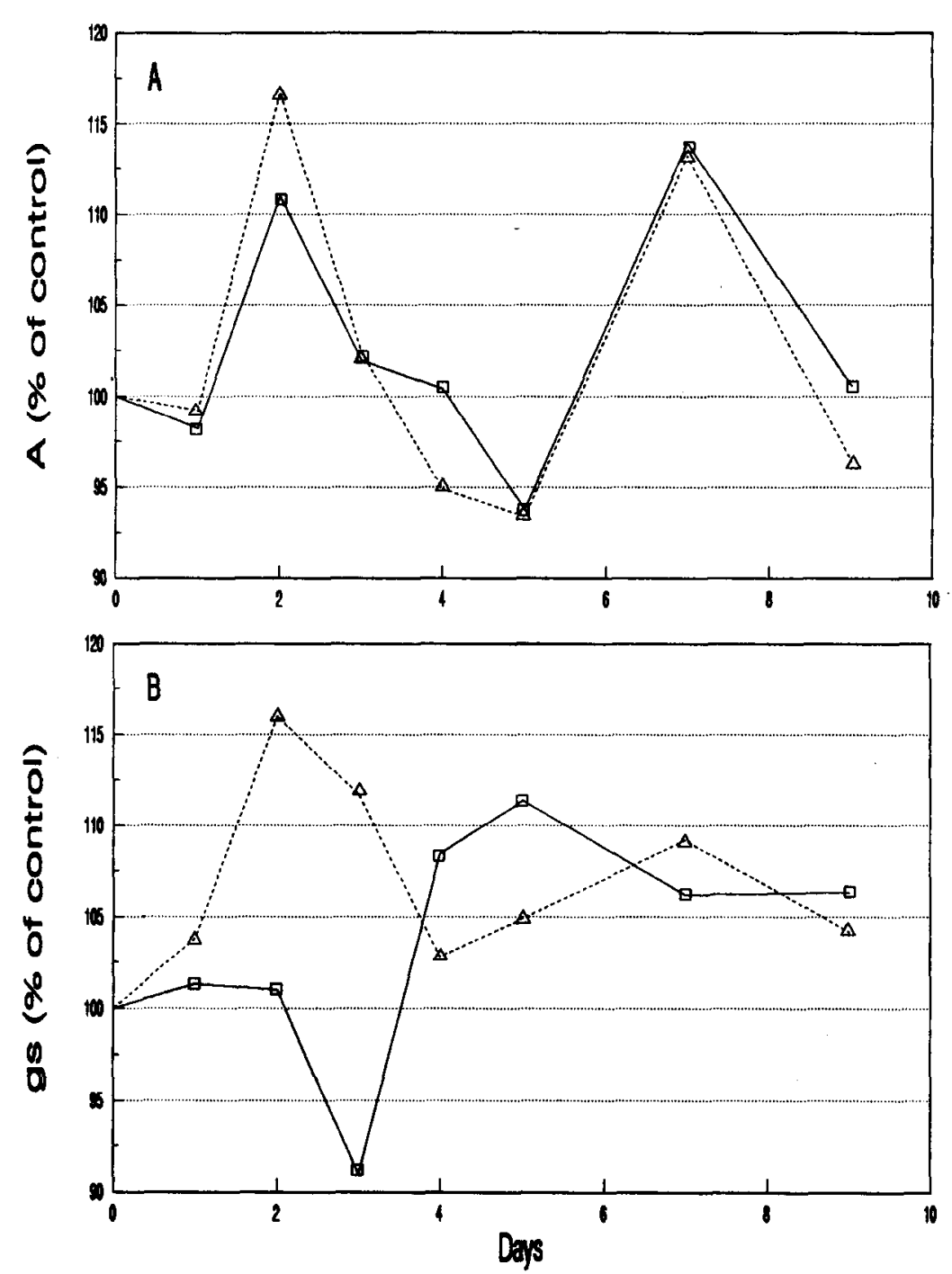

Fig. 1. Photosynthesis (A) and stomatal conductance (B) expressed as a percentage of control. Ethephon at $5(-.-)$ or $50(-) \mu l \cdot$ liter $^{-1}$. Initial values were 10.58 for $\mathbf{A}$ and 0.399 for $\mathbf{B}$.

ducted on the first fully expanded terminal leaflet under the main growing tip of each tomato plant. Gas exchange was measured using a portable system (model 6000; LICOR, Lincoln, Neb.) with a 0.25 -liter stirred cuvette. One leaflet per plant was enclosed in the sampling chamber. Measuring only one leaflet was considered sufficient after trials showed little variability within one plant. The equipment was calibrated with a standardized $\mathrm{CO}_{2}$ gas mixture. After a 30 -sec measurement period, leaflets were excised and total leaf area determined with a portable leafarea meter (model 3000, LI-COR). Measurements were taken between 10:00 and 11:00 AM Mountain Standard Time. The seven measurement days were cloudless, which resulted in a relatively stable PPF: between 600 and $800 \mu \mathrm{mol} \cdot \mathrm{m}^{-2} \cdot \mathrm{s}^{-1}$ (in the greenhouse). Temperature and humidity were $\approx 26 \mathrm{C}$ and $60 \%$, respectively. The effect of ethephon on gas-exchange characteristics was analyzed using a polynomial regression (SAS Institute, 1985).

Ethephon induced changes in gas-exchange patterns of tomato plants (Fig. 1, Table 2). Over the 9 days, photosynthesis the polynomial regression.

In general, the literature is limited on the effects of short-term ethylene exposure $(<48$ h) on plants. Madhavan et al. (1983) reported that gaseous ethylene (60 to 70 $\left.\mu \mathrm{l} \cdot \mathrm{liter}^{-1}\right)$ induced stomatal closure of tomato plants within $48 \mathrm{~h}$. Four hours after exposure to $210 \mu \mathrm{mol}$ ethylene gas $/ \mathrm{m}^{3}$, tomatoes exhibited a slight drop in photosynthetic rate, whereas stomatal conductance was slightly increased (Taylor and Gunderson, 1986). These reports correspond with our data showing no changes in photosynthetic rates following initial ethephon exposure $(24 \mathrm{~h})$, while none of the reports examined mentioned plant responses to long-term ethylene exposure.

Morphological changes were also observed in the ethephon-treated plants: leaf epinasty and formation of lenticels on the lower stems. Plants treated with the high concentration also lost vigor. Leaves became epinastic in the afternoon when radiation was highest; however, our gas-exchange measurements were taken before the onset of epinastic movement and leaves of all treatments received a uniform radiation load. Plants that received ethephon at $5 \mu \mathrm{l} \cdot$ liter $^{-1}$ showed slight ethylene-induced symptoms, which appeared to be intermediate to the plants receiving the higher ethephon concentration. The morphological changes observed in the plants exposed to $50 \mu \mathrm{l} \cdot$ liter $^{-1}$ are also commonly noted in flooded plants (Kozlowski, 1984; Tang and Kozlowski, 1984); however, in addition to epinastic movements and lenticel formation, photosynthesis and stomatal conductance usually decreased under flooded conditions (Bradford and Hsiao, 1982). These differences between flooded conditions and the ethephon treatments suggest that ethylene does not mediate depression of photosynthesis and stomatal closure. Woodrow et al. (1988) express a similar opinion. They reported that ethylene significantly altered carbon partitioning and concluded that ethylene did not alter the photosynthetic processes directly. A similar conclusion was reached by Bradford (1983). He determined that epinastic movement, and thus altered light interception, was ethylenemediated, whereas cytokinins were more directly involved with changes in the photosynthetic capacity of flooded plants. Contrariwise, in vivo ethephon studies demonstrated reduced photosynthetic activity of isolated chloroplasts (Choe and Wang, 1986). During our trial, photosynthesis and $g_{s}$ remained at or above control levels, indicating that chloroplasts, photosynthetic processes, and gas-exchange mechanisms maintained their integrity for at least 9 days.

A biphasic or multiphasic in-time response of plant gas exchange to ethylene may explain some of the inter- and intra-specific variations found in the literature. The biphasic photosynthetic response exhibited by tomato (Fig. 1) was similar to that demonstrated by Mudge (1988) for rooting enhancement during propagation trials. He reports a biphasic (in time) rooting response, with rooting being inhibited the first few hours 
following ethylene exposure, followed by several days of root promotion and thereafter a return to inhibition.

Our results suggest that observations for $<48 \mathrm{~h}$ may not render a complete synopsis of plant-ethylene interactions. We propose that plants can exhibit an analogous response, as demonstrated by Mudge (1988) in his rooting study. We do not know if this phasic response continues indefinitely and if plants require specific environmental conditions to allow these ethephon-induced responses. Our results suggest that the biphasic or multiphasic plant responses reported here and elsewhere in studies with ethylene may be fixed as opposed to random expressions of ethylene response, as reported in the scientific literature.

\section{Literature Cited}

Bradford, K.J. 1983. Involvement of plant growth substances in the alteration of leaf gas exchange of flooded tomato plants. Plant Physiol. 73:480483.

Bradford, K.J. and T.C. Hsiao. 1982. Stomata1 behavior and water relations of waterlogged tomato plants. Plant Physiol. 70:1508-1513.

Choe, H.T. and M. Wang. 1986. Effects of ethephon on aging and photosynthetic activity in isolated chloroplasts. Plant Physiol. 80:305-309.

Kozlowski, T.T. 1984. Flooding and plant growth. Academic, Orlando, Fla.

Levitt, L.K., D.B. Stein, and B. Rubenstein. 1987. Promotion of stomatal opening by indoleacetic acid and ethrel in epidermal strips of Vicia faba L. Plant Physiol. 85:318-321.

Madhavan, S., A. Chrominiski, and B.N. Smith. 1983. Effect of ethylene on stomatal opening in tomato and carnation leaves. Plant \& Cell Physiol. 24:569-572.

Manuchia, D.J. 1990. A study of the effects of ethephon on Pinus eldarica seedlings. PhD Diss., New Mexico State Univ., Las Cruces.

Manuchia, D.J. and J.W. Briedé. 1989. Ethylene influence on Pinus eldarica seedling physiology and morphology. 65th Annu. Mtg. Southwestem and Rocky Mountain Div. Amer. Assn. Adv. Sci., Las Cruces N.M.

Mudge, K.W. 1988. Effect of ethylene on rooting, p. 150-161. In: T.D. Davis (ed.). Adventitious root formation in cuttings. Dioscordis, Portland, Ore.

SAS Institute. 1985. SAS user's guide: Statistics (version 5 ed.) SAS Institute, Inc., Cary, N.C.

Tang, Z.C. and T.T. Kozlowski. 1984. Ethylene production and morphological adaptation of woody plants to flooding. Can. J. Bot. 62:16591664.

Taylor, G.E. and C.A. Gunderson. 1986. The response of foliar gas exchange to exogenously applied ethylene. Plant Physiol. 82:653-657.

Taylor, G.E. and C.A. Gunderson. 1988. Physiological site of ethylene effect on carbon dioxide assimilation in Glycine max L. Merr. Plant Physiol. 86:85-92.

Vitagliano, C. 1975. Effects of ethephon on stomata, ethylene evolution, and abscission in olive. J. Amer. Soc. Hort. Sci. 100:482-484.

Vitagliano, C. and G.V. Hoad. 1978. Leaf stomatal resistance, ethylene evolution and $\mathrm{ABA}$ levels as influenced by (2-chloroethyl) phosphonic acid. Scientia Hort. 8:101-106.

Woodrow L., R.G. Thompson, and B. Grodzinski. 1988. Effects of ethylene on photosynthesis and partitioning in tomato, Lycopersicon esculentum Mill. J. Expt. Bot. 39:667-684. 